\title{
Updated standardized endpoint definitions for transcatheter aortic valve implantation: The Valve Academic Research Consortium-2 consensus document*
}

\author{
A. Pieter Kappetein, Stuart J. Head, Philippe Généreux, Nicolo Piazza, Nicolas M. van Mieghem, \\ Eugene H. Blackstone, Thomas G. Brott, David J. Cohen, Donald E. Cutlip, Gerrit-Anne van Es, \\ Rebecca T. Hahn, Ajay J. Kirtane, Mitchell W. Krucoff, Susheel Kodali, Michael J. Mack, Roxana Mehran, \\ Josep Rodés-Cabau, Pascal Vranckx, John G. Webb, Stephan Windecker, Patrick W. Serruys, and Martin B. Leon
}

\begin{abstract}
Objectives: The aim of the current Valve Academic Research Consortium (VARC)-2 initiative was to revisit the selection and definitions of transcatheter aortic valve implantation (TAVI) clinical endpoints to make them more suitable to the present and future needs of clinical trials. In addition, this document is intended to expand the understanding of patient risk stratification and case selection.
\end{abstract}

Background: A recent study confirmed that VARC definitions have already been incorporated into clinical and research practice and represent a new standard for consistency in reporting clinical outcomes of patients with symptomatic severe aortic stenosis (AS) undergoing TAVI. However, as the clinical experience with this technology has matured and expanded, certain definitions have become unsuitable or ambiguous.

Methods and Results: Two in-person meetings (held in September 2011 in Washington, DC, and in February 2012 in Rotterdam, The Netherlands) involving VARC study group members, independent experts (including surgeons, interventional and noninterventional cardiologists, imaging specialists, neurologists, geriatric specialists, and clinical trialists), the US Food and Drug Administration (FDA), and industry representatives, provided much of the substantive discussion from which this VARC-2 consensus manuscript was derived. This document provides an overview of risk assessment and patient stratification that need to be considered for accurate patient inclusion in studies. Working groups were assigned to define the following clinical endpoints: mortality, stroke, myocardial infarction, bleeding complications, acute kidney injury, vascular complications, conduction disturbances and arrhythmias, and a miscellaneous category including relevant complications not previously categorized. Furthermore, comprehensive echocardiographic recommendations are provided for the evaluation of prosthetic valve (dys)function. Definitions for the quality of life assessments are also reported. These endpoints formed the basis for several recommended composite endpoints.

Conclusions: This VARC-2 document has provided further standardization of endpoint definitions for studies evaluating the use of TAVI, which will lead to improved comparability and interpretability of the study results, supplying an increasingly growing body of evidence with respect to TAVI and/or surgical aortic valve replacement. This initiative and document can furthermore be used as a model during current endeavors of applying definitions to other transcatheter valve therapies (for example, mitral valve repair). (J Thorac Cardiovasc Surg 2013;145:6-23)

\footnotetext{
* The Valve Academic Research Consortium (VARC) consists of representatives from several independent Academic Research Organizations, several Surgery and Cardiology Societies, members of the US Food and Drug Administration (FDA), and several independent experts. However, it is not a society document. Neither the societies nor the FDA has been asked to endorse the document.

Grants have been provided to the ARC Board including representatives of Cardialysis, the Cardiovascular Research Foundation, Duke Clinical Research Institute, and Harvard Clinical Research Institute to cover the costs of travel, meeting rooms, and lodging for academic attendees at the Washington and Rotterdam meetings by Abbott Vascular, Boston Scientific, Direct Flow Medical, Edwards Lifesciences, Heart Leaflet Technologies, Medtronic Corporation, and St. Jude Medical.

Disclosures: N. Piazza has received consultancy fees from Medtronic, his institution has received grants/grants pending from Medtronic. E.H. Blackstone has received study support from Edwards Lifesciences consultancy fees from Edwards Lifesciences. D.J. Cohen has received consultancy fees from Medtronic, his institution has received grants/grants pending from Medtronic and Edwards Lifesciences. G.A van Es is an employee of Cardialysis BV, The Netherlands. M.W. Krucoff has received study support from Edwards Lifesciences. S. Kodali is a Board member of St. Jude Medical and Thubrikar Aortic Valve and has received consultancy fees from Medtronic and Edwards Lifesciences. R. Mehran has received consultancy fees from Astra Zeneca, Janssen (Johnson \& Johnson), Regado, Abbott Laboratories, Merck Sharpe \& Dohme Corp., Maya Medical. Her institution has received grants/grants pending from BMS/Sanofi, The Medicines Company, Lilly/Daiichi
}

Sanko. J. Rodés-Cabau has received consultancy fees from Edwards Lifesciences, St. Jude Medical. J.G. Webb has received consultancy fees from Edwards Lifesciences, his institution has received grants/grants pending from Edwards Lifesciences. S. Windecker has received speakers bureaus fees from Edwards Lifesciences and Medtronic, his institution has received a Swiss National Science Foundation Grant (32003B_135807) and has grants/ grants pending from Edwards Lifesciences and Medtronic. M.B. Leon is on the advi-sory Board for Edwards Lifesciences. The others authors have declared to have no conflict of interests for this paper. The VARC meetings involved members of the Interventional Cardiology Devices Branch, of the Office of Device Evaluation, Center for Devices and Radiological Health, USFDA. The opinions or assertions herein are the private views of the authors and are not to be construed as reflect-ing the views of the FDA. The article has been copublished in the European Heart Journal, EuroIntervention, Journal of the American College of Cardiology, European Journal of CardioThoracic Surgery, and the Journal of Thoracic and Cardiovascular Surgery.

Received for publication June 28, 2012; revisions received July 24, 2012; accepted for publication July 26, 2012.

Address reprint requests to: A. Pieter Kappetein, Erasmus University Medical Center, PO Box 2040, 3000 CA Rotterdam, The Netherlands (E-mail: a.kappetein@ erasmusmc.nl).

$0022-5223 / \$ 36.00$

Copyright (C) 2013 by The American Association for Thoracic Surgery

http://dx.doi.org/10.1016/j.jtcvs.2012.09.002 


\section{INTRODUCTION}

The first Valve Academic Research Consortium (VARC) consensus manuscript was published in January 2011 with the goal of achieving consensus for (i) selecting appropriate clinical endpoints reflecting device, procedure and patientrelated effectiveness and safety, and (ii) standardizing definitions for single and composite clinical endpoints, for transcatheter aortic valve implantation (TAVI) clinical trials. ${ }^{1,2}$ A recent pooled analysis, which included 3519 patients from 16 unique studies, confirms that VARC definitions have already been incorporated into clinical and research practice and represent a new standard for consistency in reporting clinical outcomes of patients with symptomatic severe aortic stenosis (AS) undergoing TAVI. ${ }^{3}$ However, as the clinical experience with this technology has matured and expanded, certain definitions have become unsuitable or ambiguous. ${ }^{3-7}$ The aim of the current VARC was therefore to revisit the selection and definitions of TAVI-related clinical endpoints to make them more suitable to the present and future needs of clinical trials. In addition, this document is intended to expand the understanding of patient risk stratification and case selection.

Similar to the VARC-1 process, 2 in-person meetings (held in September 2011 in Washington, DC, and in February 2012 in Rotterdam, The Netherlands) involving VARC study group members, independent experts (including surgeons, interventional and noninterventional cardiologists, imaging specialists, neurologists, geriatric specialists, and clinical trialists), the US Food and Drug Administration (FDA), and industry representatives, provided much of the substantive discussion from which this VARC-2 consensus manuscript was derived (see Appendices 1 and 2).

\section{RISK SCORES AND COMORBIDITIES}

Risk stratification of patients is crucial to identifying appropriate candidates for specific cardiac procedures. The EuroSCORE and Society of Thoracic Surgeons (STS) score are the most widely used risk scores to predict operative mortality in cardiac surgery. These models were developed and validated in a standard surgical risk population. The predictive power of both models is therefore suboptimal in high-risk patients with valvular disease, although the STS score has shown to outperform the Logistic EuroSCORE. ${ }^{8}$ These models are even more limited in application to patients who are considered at prohibitive risk for cardiac surgery, a cohort that could particularly benefit from TAVI. Current models could be improved by the addition of specific clinical and anatomical variables that affect mortality. ${ }^{9}$ As an example, the presence of a porcelain aorta and frailty are important factors not included in either risk model but are routinely considered during patient evaluation (Figure 1 and Table 1).
Perhaps the most important patient characteristic not included in current risk models is frailty. ${ }^{10}$ Frailty is frequently assessed subjectively based upon an informal "eyeball test". However, physical performance assessments such as gait speed and grip strength are more objective performance measures that may capture an individual's overall functional status. ${ }^{11}$ These continuous measures are reproducible and can be reassessed at various time points. In addition, they require no language translation. Assessments of cognition, weight (loss), activity level, and independence in the activities of daily living provide additional information on the overall health state of the individual. ${ }^{11}$ These limitations are more often found in patients with a high comorbidity burden and may coexist with certain laboratory findings (eg, low serum albumin, elevated inflammatory markers, anemia) that further reflect the health state and physiological reserve of the frail patient.

Baseline evaluation of the presence of cognitive dysfunction (mild cognitive impairment or dementia) has also emerged as an essential part of the initial risk stratification, especially in older populations, where the risk, benefit, and cost-effectiveness of invasive procedures must be weighed judiciously. Preprocedural cognitive assessment may also help avoid attributing postprocedural mental status changes to stroke categories. Among the several clinically established rating scales (eg, Mini-Mental State Examination, modified Telephone Interview of Cognitive Status [TICS-M], Clinical Dementia Rating Scale), ${ }^{12}$ there is no particular standard for TAVI. Nevertheless, some systematic cognitive assessment by neuropsychological experts should be a part of the initial heart team evaluation.

Table 1 provides an overview of these and other risk factors (Figures 1-3) and VARC-2 recommendations on how each should be assessed. In clinical trials, it will be important to capture variables that predict extreme operative risk and to standardize the evaluation criteria and process. This will help to determine which subsets of patients are likely to benefit from TAVI treatment.

\section{PATIENT STRATIFICATION: THE HEART TEAM APPROACH}

Valve Academic Research Consortium-2 recommends the use of a heart team for patient evaluation. The heart team should consist of at least (interventional) cardiologists, cardiovascular surgeons, and imaging specialists, but its composition is dynamic and can also include anesthesiologists, geriatricians, neurologists, etc. This multi-disciplinary team should convene as a group on a regular basis to review and interpret clinical data to arrive at a consensus on the optimal treatment strategy for each patient. The heart team approach also allows for the adjustment of the decision-making process according to local experience and circumstances. 

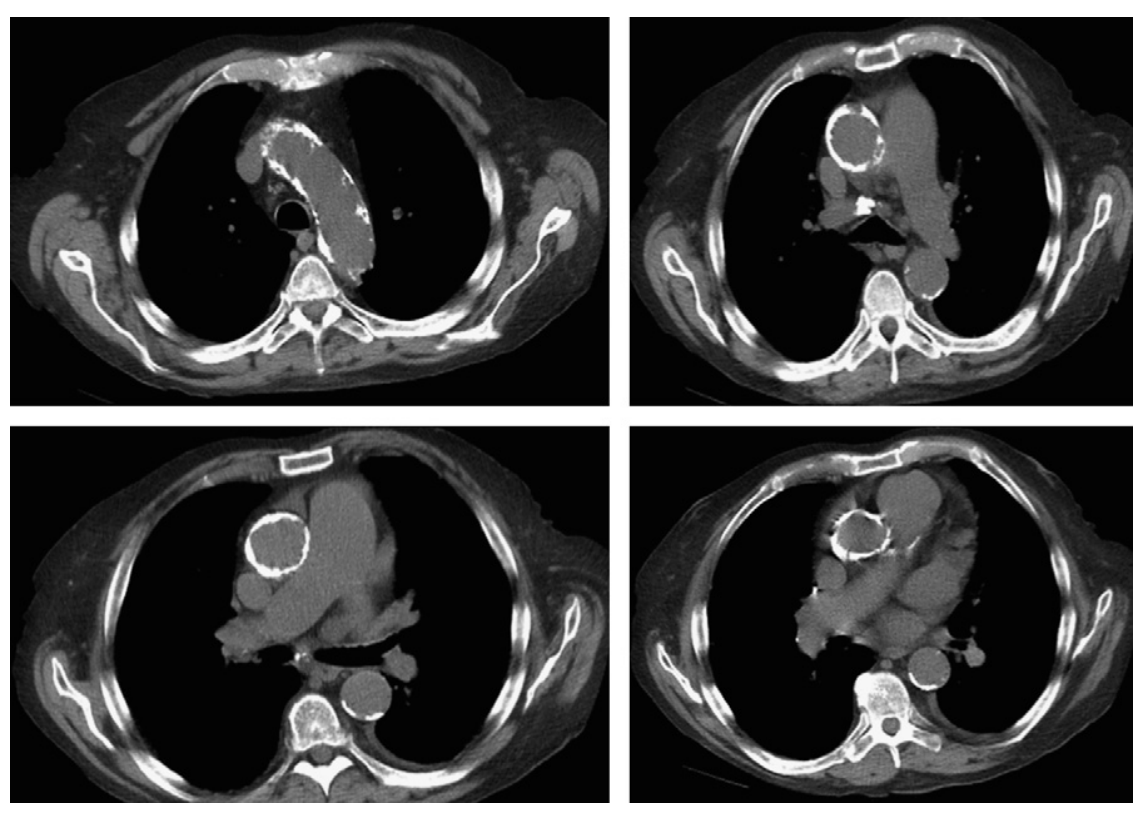

FIGURE 1. Porcelain aorta or severely atherosclerotic aorta.

The heart team should agree on an estimated 30-day mortality risk for each patient based upon integrating a careful clinical assessment and utilizing appropriate risk prediction scoring systems, preferably the STS score. Surgical mortality risk strata are difficult to precisely assign, but an estimated 30-day mortality of $<4 \%$ is considered low risk, $4 \%-10 \%$ is intermediate risk, $>10 \%$ is high risk, and $>15 \%$ is very high risk. A patient is considered at extreme risk if at least 2 cardiovascular surgeons from a tertiary centre of excellence deny surgery because of prohibitive operative risks, estimated to be a combined $>50 \%$ risk of irreversible morbidity or mortality. ${ }^{13}$ In addition to the specific risk factors that can prohibit patients from undergoing TAVI or surgical aortic valve replacement (SAVR) (Table 1), the operative risk assessment is also important to identify patients who are likely not to benefit from either TAVI or SAVR (the so-called "futility" category of highrisk patients). An expected improvement in the quality of life (QOL) may further be necessary to identify treatment responders versus non-responders. Individualized life expectancy assumptions should be incorporated by the heart team in the clinical decision-making process as a central factor in weighing the risk-benefit ratio. Prognostic indices of life expectancy may play a central role in moving beyond arbitrary age-based cut-offs. ${ }^{14}$

The most important role of the heart team is to provide customized management decisions for common and unusual clinical scenarios in terms of patient selection, procedural performance, and complication management. An example is the frequent situation of severe AS and concomitant coronary artery disease (CAD). The complexity of CAD and appropriate revascularization strategies in the setting of
AS should be determined by consensus from interventional cardiologists and cardiovascular surgeons. ${ }^{15,16}$ In new TAVI clinical trials, angiographic risk scores (eg, SYNTAX score) may be utilized to help determine the complexity of CAD, as a basis for the inclusion in the trial. Thresholds for coronary revascularization and the choice for a staged or concomitant PCI with TAVI should be guided by the complexity of the CAD and other factors as determined by the heart team. ${ }^{17,18}$ In general, the plan to deal with other coexisting conditions (such as atrial fibrillation [AF], other valvular lesions, and other congenital lesions) should be prespecified and all complications encountered in the treatment of associated conditions (including treatment after the TAVI procedure) should be captured. Such thorough preprocedural assessment is also valuable in discriminating new postprocedural complications from simple exacerbations of pre-existing conditions.

\section{CLINICAL ENDPOINTS \\ Mortality}

In addition to the original VARC definitions, VARC-2 recommends the collection of immediate procedural mortality to capture intra-procedural events that result in immediate or consequent death $\leq 72 \mathrm{~h}$ postprocedure. Taking into account the surgical literature, procedural mortality consists of all-cause mortality within 30 days or during index procedure hospitalization -if the postoperative length of stay is longer than 30 days.

The cause of death should be captured, based on a careful review of narrative summaries and source material. Allcause, cardiovascular, and noncardiovascular mortality should be reported after 30 days during the follow-up 
TABLE 1. Risk factors not captured by traditional risk scores

\begin{tabular}{ll}
\hline Comorbidities & Definition/criteria \\
\hline Porcelain aorta or severely atherosclerotic aorta & $\begin{array}{c}\text { Heavy circumferential calcification or severe } \\
\text { atheromatous plaques of the entire ascending } \\
\text { aorta extending to the arch such that aortic } \\
\text { cross-clamping is not feasible }\end{array}$ \\
& \\
Frailty & Slowness, weakness, exhaustion, wasting and \\
& malnutrition, poor endurance and inactivity, \\
& loss of independence \\
Criteria: & $5 \mathrm{~m}$ walking time* \\
Grip strength* & BMI $<20 \mathrm{~kg} / \mathrm{m}^{2}$ and/or weight loss $5 \mathrm{~kg} / \mathrm{year}$ \\
Serum albumin $<3.5 \mathrm{~g} / \mathrm{dL}$ \\
Cognitive impairment or dementia \\
Any of the following: \\
Child-Pugh class C \\
MELD score $\geq 10$ \\
Portal-caval, spleno-renal, or transjugular \\
intrahepatic portal shunt \\
Biopsy proven cirrhosis with portal \\
hypertension or hepatocellular \\
dysfunction
\end{tabular}

Hostile chest

IMA or other critical conduit(s) crossing midline and/or adherent to posterior table of sternum

Severe pulmonary hypertension

Severe right ventricular dysfunction
Any of the following or other reasons that make redo operation through sternotomy or right anterior thoracotomy prohibitively hazardous:

Abnormal chest wall anatomy due to severe kyphoscoliosis or other skeletal abnormalities (including thoracoplasty, Potts' disease)

Complications from prior surgery

Evidence of severe radiation damage (eg, skin burns, bone destruction, muscle loss, lung fibrosis, or esophageal stricture)

History of multiple recurrent pleural effusions causing internal adhesions

A patent IMA graft that is adherent to the sternum such that injuring it during reoperation is likely. A patient may be considered at extreme risk if any of the following are present:

The conduit(s) are radiographically indistinguishable from the posterior table of the sternum.

The conduit(s) are radiographically distinguishable from the posterior table of the sternum but lie within $2-3 \mathrm{~mm}$ of the posterior table.

Primary or secondary pulmonary hypertension with PA systolic pressures greater than twothirds of systemic pressure

Criteria as defined by the guidelines (eg, TAPSE $<15 \mathrm{~mm}$, RV end-systolic area $>20 \mathrm{~cm}^{2}$, etc $) \dagger$
Diagnostic modalities

Noncontrast axial CT at levels:

Sinotubular junction

Tubular ascending aorta between the sinotubular junction and the innominate artery

Innominate artery

Entire transverse arch

Medical history

Physical examination

Physical performance measures

Cognitive assessments

Laboratory tests

Medical history

Physical examination

Laboratory tests

Child-Pugh classification

MELD score

Liver biopsy

Medical history

Physical examination

Chest x-ray

CT scan

Axial CT scan images illustrating the graft crossing the midline so that the distance from sternum to graft can be measured.

Angiogram from the lateral and PA projections and/or a CPR or VR (volume rendering) 3D reconstructed $\mathrm{CT}$ scan image showing relationships between the graft and the sternum

Echocardiography, right and left-heartcatheterization documenting PA and systemic pressures

Documentation of secondary causes of pulmonary hypertension

$C T$, Computed tomography; $B M I$, body mass index; $M E L D$, Model for End-Stage Liver Disease; $C P R$, curved planar reformation; $R V$, right ventricular; IMA, internal mammary artery; $P A$, pulmonary artery; TAPSE, tricuspid annular plane systolic excursion. *Variable with respect to age and gender without validated scientific thresholds. $\dagger$ Rudski et al. ${ }^{71}$ 


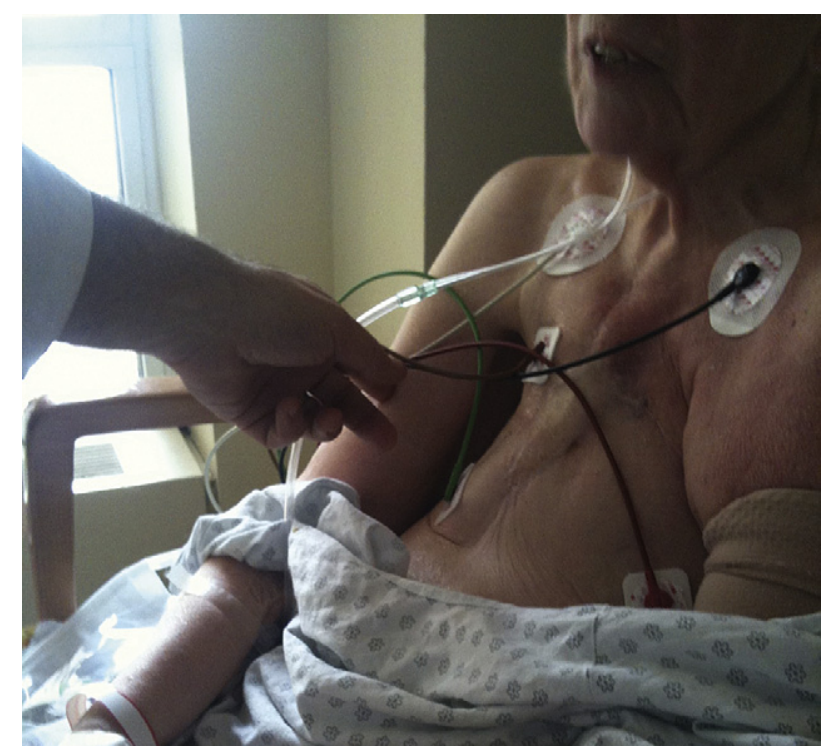

FIGURE 2. Hostile chest.

(Table 2). In determining the cause of death, the adjudication committee should consider the clinical context at the time of the index procedure and during the time interval leading up to death. All efforts (including the use of national death registries) should be made to identify, precisely characterize, and appropriately classify any death.

\section{Myocardial Infarction}

Myocardial injury as determined by a significant rise in cardiac biomarkers occurs frequently following TAVI, and a significant magnitude of myocardial injury has been associated with worse outcomes. ${ }^{19}$ Valve Academic Research Consortium-2 recommends the systematic collection of biomarkers of myocardial injury prior to the procedure, within 12-24 $\mathrm{h}$ after the procedure, at $24 \mathrm{~h}$ thereafter, at $72 \mathrm{~h}$ or at discharge, and, if still elevated, daily until values show a decline. Similar to the previous VARC recommendations, the definition of periprocedural $(\leq 72 \mathrm{~h}$ following TAVI) MI will be based on a combination of clinical criteria and cardiac biomarkers. However, the threshold values have been adjusted (Table 3). Acute ischemic events occurring after $72 \mathrm{~h}$ should be considered spontaneous myocardial infarctions and defined in accordance with the universal MI guidelines. $^{20}$

\section{Stroke}

With increasing attention to stroke as an important periprocedural complication of TAVI, ${ }^{21}$ the FDA has emphasized the need for an accurate assessment of stroke and has participated actively in recommending specific details of the VARC-2 definitions. In an attempt to further align with the fundamental definitions now endorsed by the FDA, ${ }^{22}$ consensus was reached at VARC- 2 to further refine the definition of stroke and recommend the use of these definitions in future TAVI clinical trials (Table 4). The definitions endorsed by the FDA are intended to apply to a wide range of clinical trials and to enable those trials to assess the clinically relevant consequences of vascular brain injury for determining the safety or effectiveness of an intervention.

Stroke is defined as an acute episode of focal or global neurological dysfunction caused by the brain, spinal cord, or retinal vascular injury as a result of hemorrhage or
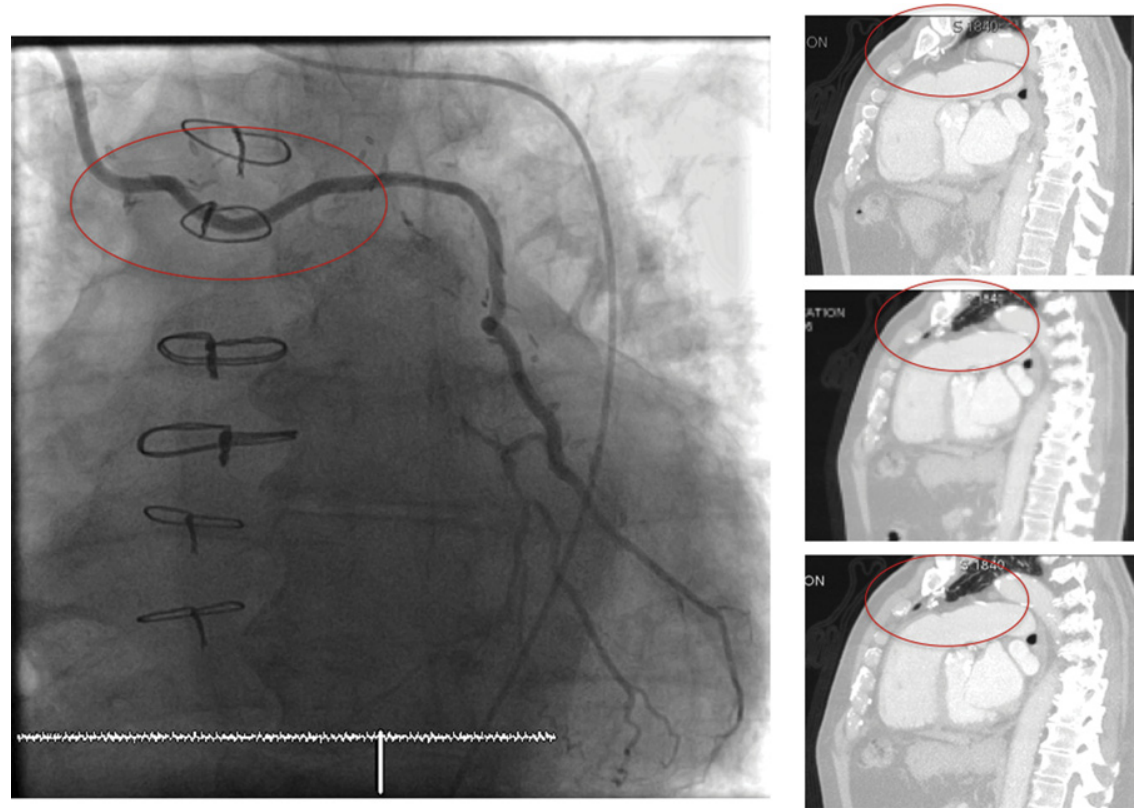

FIGURE 3. Patent IMA graft crossing midline and/or adherent to the posterior table of sternum. 
TABLE 2. Mortality

All-cause mortality

Cardiovascular mortality

Any of the following criteria

Death due to proximate cardiac cause (eg, myocardial infarction, cardiac tamponade, worsening heart failure)

Death caused by noncoronary vascular conditions such as neurological events, pulmonary embolism, ruptured aortic aneurysm, dissecting aneurysm, or other vascular disease

All procedure-related deaths, including those related to a complication of the procedure or treatment for a complication of the procedure

All valve-related deaths including structural or nonstructural valve dysfunction or other valve-related adverse events

Sudden or unwitnessed death

Death of unknown cause

Noncardiovascular mortality

Any death in which the primary cause of death is clearly related to another condition (eg, trauma, cancer, suicide)

infarction. Stroke may be classified as ischemic or hemorrhagic with appropriate subdefinitions. Ischemic stroke is defined as an acute episode of focal cerebral, spinal, or retinal dysfunction caused by infarction of central nervous system tissue. Hemorrhagic stroke is defined as an acute episode of focal or global cerebral or spinal dysfunction caused by intraparenchymal, intraventricular, or subarachnoid hemorrhage. A stroke may be classified as "undetermined" if there is insufficient information to allow the categorization as ischemic or hemorrhagic.

An entity closely related to an ischemic stroke that should be assessed is a transient ischemic attack (TIA). Transient ischemic attack is defined as a transient episode of focal neurological dysfunction caused by the brain, spinal cord, or retinal ischemia, without acute infarction. The difference between TIA and ischemic stroke is the presence of tissue damage on neuro-imaging studies or new sensory-motor deficit persisting $>24 \mathrm{~h}$. By definition, a TIA does not produce a lasting disability.

Valve Academic Research Consortium-2 recognizes that an assessment of stroke is incomplete without an appropriate measurement of the disability resulting from the stroke. Valve Academic Research Consortium-2 recommends the use of the modified Rankin Scale (mRS) to assess this clinical disability. ${ }^{23-25}$ The assessment of the mRS should occur at all scheduled visits in a trial and at 90 days after the onset of any stroke. This approach will maximize the detection of new or recurrent strokes, assist in the ongoing evaluation of events previously determined as TIAs, and provide an accepted and reliable indicator of the long-term impact of a given stroke.

Previously, VARC recommended categorizing strokes as "major" and "minor" based upon mRS scores. To enhance the accuracy in the description of a given stroke and to provide accurate categorization of strokes within a given trial,
VARC-2 now recommends the use of the terms "disabling" and "nondisabling." A disabling stroke is one that results (at 90 days after stroke onset) in an mRS score of $\geq 2$ and an increase in $\geq 1 \mathrm{mRS}$ category from an individual's prestroke baseline. A nondisabling stroke is one that results (at 90 days after stroke onset) in an mRS score of $<2$ or that does not result in an increase in $\geq 1 \mathrm{mRS}$ category from an individual's prestroke baseline. In addition to this categorization of disabling and nondisabling strokes, the endpoint of all strokes should be reported.

Although brain imaging (typically, MRI for acute and chronic ischemia and hemorrhage, and CT for acute and chronic hemorrhage and chronic ischemia) is often used to supplement the clinical diagnosis of stroke, ${ }^{26}$ a diagnosis of stroke may be made on clinical grounds alone. Valve Academic Research Consortium-2 recognizes that stroke symptoms are protean and not well suited to a prespecified itemized listing. Accordingly, VARC-2 recommends that a vascular neurologist experienced in clinical trials involving stroke be included in all phases of trial planning, execution, and monitoring, including involvement in the Clinical Events Committee and the Data and Safety Monitoring Board.

New insights into the timing of events show delayed or late occurrence of strokes, beyond the early postimplantation phase. ${ }^{27}$ This may suggest that the cause of stroke is additionally related to other factors or patient susceptibilities and should necessitate active investigation of devices and adjunctive pharmacotherapy to reduce the frequency and severity of strokes after TAVI, including precise documentation of the use and dosage of antithrombotic and antiplatelet medication. Patient baseline characteristics (eg, carotid stenosis) and postoperative complications (eg, AF) need to be carefully documented to be able to identify the contributing causes of stroke.

Invasive stroke management (catheter-based intracranial intervention) is gaining an increasingly important role and may impact morbidity and mortality. Valve Academic Research Consortium-2 therefore recommends the ascertainment of any acute stroke management strategy (eg, aspiration, thrombolysis, or conservative management).

\section{Bleeding Complications}

Valve Academic Research Consortium-2 acknowledges the fact that the Bleeding Academic Research Consortium (BARC) recently convened and established standardized bleeding definitions for patients receiving antithrombotic therapy and undergoing coronary revascularization (PCI or CABG). ${ }^{28,29}$ However, because the current definitions have been well adopted and shown to be accurate in predicting adverse events, ${ }^{30}$ VARC-2 has chosen to maintain the original VARC definitions with BARC classifications (Table 5), recognizing that future validation of BARC criteria in this population may warrant revision of the current recommendations. 
TABLE 3. Myocardial infarction

Periprocedural MI ( $\leq 72 \mathrm{~h}$ after the index procedure)

New ischemic symptoms (eg, chest pain or shortness of breath), or new ischemic signs (eg, ventricular arrhythmias, new or worsening heart failure, new ST-segment changes, hemodynamic instability, new pathological Q-waves in at least 2 contiguous leads, imaging evidence of new loss of viable myocardium or new wall motion abnormality) AND

Elevated cardiac biomarkers (preferable CK-MB) within $72 \mathrm{~h}$ after the index procedure, consisting of at least 1 sample postprocedure with a peak value exceeding $15 \times$ as the upper reference limit for troponin or $5 \times$ for CK-MB.* If cardiac biomarkers are increased at baseline ( $>99$ th percentile), a further increase in at least $50 \%$ postprocedure is required AND the peak value must exceed the previously stated limit Spontaneous MI ( $>72 \mathrm{~h}$ after the index procedure)

Any 1 of the following criteria:

Detection of rise and/or fall of cardiac biomarkers (preferably troponin) with at least 1 value above the 99th percentile URL, together with the evidence of myocardial ischemia with at least 1 of the following:

Symptoms of ischemia

ECG changes indicative of new ischemia [new ST-T changes or new left bundle branch block (LBBB)]

New pathological Q-waves in at least 2 contiguous leads

Imaging evidence of a new loss of viable myocardium or new wall motion abnormality

Sudden, unexpected cardiac death, involving cardiac arrest, often with symptoms suggestive of myocardial ischemia, and accompanied by presumably new ST elevation, or new LBBB, and/or evidence of fresh thrombus by coronary angiography and/or at autopsy, but death occurring before blood samples could be obtained, or at a time before the appearance of cardiac biomarkers in the blood.

Pathological findings of an acute myocardial infarction

*Previously in the original VARC it was $10 \times$ and $5 \times$ for troponin and CK-MB respectively.

With respect to blood transfusions, it is critical to acknowledge that a bleeding complication has to be the result of overt bleeding and cannot be adjudicated based on blood transfusions alone.

\section{Acute Kidney Injury}

The original VARC definitions recommended the use of a modified version of the RIFLE classification. However, we now recommend using the AKIN system (Table 6), which is a modified version of RIFLE that has been adopted by many in the nephrology community, including the KDIGO initiative. ${ }^{31,32}$ As a result, acute kidney injury (AKI) can also be diagnosed according to urine output measures (Table 6).

In comparison with the original VARC, the timing for the diagnosis of AKI is extended from $72 \mathrm{~h}$ to 7 days. Patients who experience AKI should have follow-up renal function assessments after 7 days until stabilization.

\section{Vascular Complications}

Table 7 lists VARC-2 definitions for major and minor vascular complications. Further clarifications of these
TABLE 4. Stroke and TIA

Diagnostic criteria

Acute episode of a focal or global neurological deficit with at least 1 of the following: change in the level of consciousness, hemiplegia, hemiparesis, numbness, or sensory loss affecting 1 side of the body, dysphasia or aphasia, hemianopia, amaurosis fugax, or other neurological signs or symptoms consistent with stroke

Stroke: duration of a focal or global neurological deficit $\geq 24 \mathrm{~h}$; OR $<24$ $\mathrm{h}$ if available neuroimaging documents a new hemorrhage or infarct; OR the neurological deficit results in death

TIA: duration of a focal or global neurological deficit $<24 \mathrm{~h}$, any variable neuroimaging does not demonstrate a new hemorrhage or infarct

No other readily identifiable nonstroke cause for the clinical presentation (eg, brain tumor, trauma, infection, hypoglycemia, peripheral lesion, pharmacological influences), to be determined by or in conjunction with the designated neurologist*

Confirmation of the diagnosis by at least 1 of the following:

Neurologist or neurosurgical specialist

Neuroimaging procedure (CT scan or brain MRI), but stroke may be diagnosed on clinical grounds alone

Stroke classification

Ischemic: an acute episode of focal cerebral, spinal, or retinal dysfunction caused by infarction of the central nervous system tissue

Hemorrhagic: an acute episode of focal or global cerebral or spinal dysfunction caused by intraparenchymal, intraventricular, or subarachnoid hemorrhage

A stroke may be classified as undetermined if there is insufficient information to allow categorization as ischemic or hemorrhagic

Stroke definitions $\dagger$

Disabling stroke: an mRS score of 2 or more at 90 days and an increase in at least $1 \mathrm{mRS}$ category from an individual's prestroke baseline

Nondisabling stroke: an mRS score of $<2$ at 90 days or one that does not result in an increase in at least $1 \mathrm{mRS}$ category from an individual's prestroke baseline

$\overline{m R S \text {, Modified Rankin Scale. *Patients with nonfocal global encephalopathy will not }}$ be reported as a stroke without unequivocal evidence of cerebral infarction-based upon neuroimaging studies (CT scan or Brain MRI). †Modified Rankin Scale assessments should be made by qualified individuals according to a certification process. $^{23-25}$

definitions to supplement the original VARC document are as follows. Preplanned surgical access or a planned endovascular approach to vascular closure (eg, "preclosure" $)^{33,34}$ should be considered as part of the TAVI procedure and not as a complication, unless untoward clinical consequences are documented (eg, bleeding complications, limb ischemia, distal embolization, or neurological impairment). Unplanned endovascular stenting or surgical repair for any vascular complications during the index procedure without other clinical sequelae should be considered a minor vascular complication, except if associated with qualifying consequences (Table 7). Complications related to alternative access sites, including the left-ventricular apex, subclavian artery, or aorta should be systematically recorded. To ensure accurate 
TABLE 5. Bleeding

Life-threatening or disabling bleeding

Fatal bleeding (BARC type 5) OR

Bleeding in a critical organ, such as intracranial, intraspinal, intraocular, or pericardial necessitating pericardiocentesis, or intramuscular with compartment syndrome (BARC type $3 b$ and $3 c$ ) OR

Bleeding causing hypovolemic shock or severe hypotension requiring vasopressors or surgery (BARC type $3 b$ ) OR

Overt source of bleeding with drop in hemoglobin $\geq 5 \mathrm{~g} / \mathrm{dL}$ or whole blood or packed red blood cells (RBCs) transfusion $\geq 4$ units* (BARC type $3 b)$

Major bleeding (BARC type $3 a$ )

Overt bleeding either associated with a drop in the hemoglobin level of at least $3.0 \mathrm{~g} / \mathrm{dL}$ or requiring transfusion of 2 or 3 units of whole blood/RBC, or causing hospitalization or permanent injury, or requiring surgery AND

Does not meet criteria of life-threatening or disabling bleeding Minor bleeding (BARC type 2 or 3a, depending on the severity)

Any bleeding worthy of clinical mention (eg, access site hematoma) that does not qualify as life-threatening, disabling, or major

$B A R C$, Bleeding Academic Research Consortium ${ }^{29} ; R B C$, red blood cell. *Given that 1 unit of packed RBC typically will raise the hemoglobin concentration by $1 \mathrm{~g} / \mathrm{dL}$, an estimated decrease in hemoglobin will be calculated.

capture of these elements, VARC-2 strongly recommends that detailed information regarding the access site and preplanned vascular closure technique be recorded as well as the use of any additional unplanned access or closure techniques (surgical repair, endovascular stenting, or endovascular balloon therapy). Since many vascular complications will also result in a bleeding complication, events that meet VARC-2 definitions for both categories should be reported in both categories. Finally, VARC-2 recommends that all vascular complications be recorded as either access (eg, iliac rupture) or nonaccess site-related (eg, ascending aorta dissection or rupture unless aortic access is used and the event originates from the cannulation site).

\section{TABLE 6. Acute kidney injury (AKIN classification*)}

Stage 1

Increase in serum creatinine to $150 \%-199 \%(1.5-1.99 \times$ increase compared with baseline) OR increase of $\geq 0.3 \mathrm{mg} / \mathrm{dL}$ ( $\geq 26.4$ $\mathrm{mmol} / \mathrm{L}) \mathrm{OR}$

Urine output $<0.5 \mathrm{~mL} / \mathrm{kg} / \mathrm{h}$ for $>6$ but $<12 \mathrm{~h}$

Stage 2

Increase in serum creatinine to $200 \%-299 \%(2.0 \%-2.99 \%$ increase compared with baseline) $\mathrm{OR}$

Urine output $<0.5 \mathrm{~mL} / \mathrm{kg} / \mathrm{h}$ for $>12$ but $<24 \mathrm{~h}$

Stage $3 \dagger$

Increase in serum creatinine to $\geq 300 \%$ ( $>3 \times$ increase compared with baseline) OR serum creatinine of $\geq 4.0 \mathrm{mg} / \mathrm{dL}$ ( $\geq 354 \mathrm{mmol} / \mathrm{L}$ ) with an acute increase of at least $0.5 \mathrm{mg} / \mathrm{dL}(44 \mathrm{mmol} / \mathrm{L}) \mathrm{OR}$

Urine output $<0.3 \mathrm{ml} / \mathrm{kg} / \mathrm{h}$ for $\geq 24 \mathrm{~h} \mathrm{OR}$

Anuria for $\geq 12 \mathrm{~h}$

The increase in creatinine must occur within $48 \mathrm{~h} .{ }^{*}$ Mehta et al. ${ }^{31} \dagger$ Patients receiving renal replacement therapy are considered to meet Stage 3 criteria irrespective of other criteria.
TABLE 7. Vascular access site and access-related complications

Major vascular complications

Any aortic dissection, aortic rupture, annulus rupture, left ventricle perforation, or new apical aneurysm/pseudoaneurysm OR

Access site or access-related vascular injury (dissection, stenosis, perforation, rupture, arterio-venous fistula, pseudoaneurysm, hematoma, irreversible nerve injury, compartment syndrome, percutaneous closure device failure) leading to death, lifethreatening or major bleeding,* visceral ischemia, or neurological impairment OR

Distal embolization (noncerebral) from a vascular source requiring surgery or resulting in amputation or irreversible end-organ damage OR

The use of unplanned endovascular or surgical intervention associated with death, major bleeding, visceral ischemia or neurological impairment OR

Any new ipsilateral lower extremity ischemia documented by patient symptoms, physical exam, and/or decreased or absent blood flow on lower extremity angiogram OR

Surgery for access site-related nerve injury OR

Permanent access site-related nerve injury

Minor vascular complications

Access site or access-related vascular injury (dissection, stenosis, perforation, rupture, arterio-venous fistula, pseudoaneuysms, hematomas, percutaneous closure device failure) not leading to death, life-threatening or major bleeding, ${ }^{*}$ visceral ischemia, or neurological impairment OR

Distal embolization treated with embolectomy and/or thrombectomy and not resulting in amputation or irreversible end-organ damage OR

Any unplanned endovascular stenting or unplanned surgical intervention not meeting the criteria for a major vascular complication OR

Vascular repair or the need for vascular repair (via surgery, ultrasoundguided compression, transcatheter embolization, or stent-graft)

Percutaneous closure device failure

Failure of a closure device to achieve hemostasis at the arteriotomy site leading to alternative treatment (other than manual compression or adjunctive endovascular ballooning)

*Refers to VARC bleeding definitions.

\section{Conduction Disturbances and Arrhythmias}

Valve Academic Research Consortium-2 proposes the systematic collection of data on the frequency of implant-related new and/or worsened conduction disturbances and the incidence and indication for permanent pacemaker implantation (Table 8). In addition, the frequency of specific arrhythmias following TAVI should be recorded as they may result in prolonged hospitalization and impaired clinical outcomes. New-onset AF (or flutter) is diagnosed as any arrhythmia within hospitalization that has the ECG characteristics of AF and lasts sufficiently long to be recorded on a 12-lead ECG, or for at least $30 \mathrm{~s}$ on a rhythm strip. ${ }^{35}$ The therapeutic approach to newonset AF (spontaneous conversion, electrical or medical cardioversion, initiation of oral anticoagulation, and rate or rhythm control medications) and any clinical 
TABLE 8. Conduction disturbances and arrhythmias

Up to $72 \mathrm{~h}$, continuous rhythm monitoring is recommended in order to maximize the detection of arrhythmias

Data elements to be collected should include

Baseline conduction abnormalities, paroxysmal or permanent atrial fibrillation (or flutter), and the presence of permanent pacemaker*

Implant-related new or worsened cardiac conduction disturbance (new or worsened first-degree atrioventricular (AV) block, second-degree AV block (Mobitz I or Mobitz II), third-degree AV block, incomplete right bundle branch block, right bundle branch block, intraventricular conduction delay, left bundle branch block, left anterior fascicular block, or left posterior fascicular block, including block requiring a permanent pacemaker implant

Persistent or transient high-degree AV block. High-grade AV block is persistent if it is present every time the underlying rhythm is checked

New permanent pacemaker implantation, with precision of the indication and the number of days postimplant of the placement of new permanent pacemaker

New-onset atrial fibrillation (or flutter) $\dagger$

Any new arrhythmia resulting in hemodynamic instability or requiring therapy $\ddagger$

*Type of permanent pacemaker should be recorded (eg, defibrillator, single vs dual chamber, biventricular). $\nmid$ New-onset atrial fibrillation (or flutter) is diagnosed as any arrhythmia within hospitalization that has the ECG characteristics of atrial fibrillation (or flutter) and lasts sufficiently long to be recorded on a 12-lead ECG, or at least $30 \mathrm{~s}$ on a rhythm strip. $\ddagger$ Therapy includes electrical/medical cardioversion or initiation of a new medication (oral anticoagulation, rhythm, or rate controlling therapy).

consequences should be thoroughly documented in the case report form.

\section{Other TAVI-Related Complications}

The original VARC document recommended the collection of a number of TAVI-related complications, but did not provide specific endpoint definitions for several endpoints. Valve Academic Research Consortium-2 recommends reporting any other complications related to the TAVI procedure, even those occurring less frequently, and provides formal VARC-2 definitions (Table 9). ${ }^{36-38}$

\section{Additional Considerations}

For studies or trials where the occurrence, prevention, or treatment of cerebral infarction is a fundamental feature (eg, embolic protection devices) additional appropriate imaging in all or a subset of patients may be necessary to allow determination of effectiveness.

\section{VALVULAR FUNCTION}

Valve Academic Research Consortium-2 maintains the original recommendations to use echocardiography as the primary imaging modality for the assessment of prosthetic valve function. ${ }^{39}$ This should include the valve position, morphology, function, and evaluation of the left ventricle (LV) and right ventricle (RV) size and function. The suggested time points for routine follow-up transthoracic echocardiography (TTE) following valve implantation are:
TABLE 9. Other TAVI-related complications

Conversion to open surgery

Conversion to open sternotomy during the TAVI procedure secondary to any procedure-related complications

Unplanned use of cardiopulmonary bypass (CPB)

Unplanned use of CPB for hemodynamic support at any time during the TAVI procedure

Coronary obstruction

Angiographic or echocardiographic evidence of a new, partial or complete, obstruction of a coronary ostium, either by the valve prosthesis itself, the native leaflets, calcifications, or dissection, occurring during or after the TAVI procedure

Ventricular septal perforation

Angiographic or echocardiographic evidence of a new septal perforation during or after the TAVI procedure

Mitral valve apparatus damage or dysfunction

Angiographic or echocardiographic evidence of new damage (chordae papillary muscle, or to the leaflet) to the mitral valve apparatus or dysfunction (eg, restrictions due to the THV) of the mitral valve during or after the TAVI procedure

Cardiac tamponade

Evidence of a new pericardial effusion associated with hemodynamic instability and clearly related to the TAVI procedure

Endocarditis

Any 1 of the following:

Fulfilment of the Duke endocarditis criteria*

Evidence of abscess, paravalvular leak, pus, or vegetation confirmed as secondary to infection by histological or bacteriological studies during a reoperation

Findings of abscess, pus, or vegetation involving a repaired or replaced valve during an autopsy

Valve thrombosis

Any thrombus attached to or near an implanted valve that occludes part of the blood flow path, interferes with valve function, or is sufficiently large to warrant treatment. Note that valve-associated thrombus identified at autopsy in a patient whose cause of death was not valve-related should not be reported as valve thrombosis

Valve malpositioning

Valve migration

After initial correct positioning, the valve prosthesis moves upwards or downwards, within the aortic annulus from its initial position, with or without consequences

Valve embolization

The valve prosthesis moves during or after deployment such that it loses contact with the aortic annulus

Ectopic valve deployment

Permanent deployment of the valve prosthesis in a location other than the aortic root

TAV-in-TAV deployment

An additional valve prosthesis is implanted within a previously implanted prosthesis because of suboptimal device position and/or function, during or after the index procedure

$\overline{T A V I}$, Transcatheter aortic valve implantation; $T H V$, transcatheter heart valve. *Durack et al. ${ }^{72}$

immediately (before discharge) following the implantation for transarterial approaches or within 30 days for transapical or transaortic approaches, 6 months following 
TABLE 10. Prosthetic valve dysfunction

\begin{tabular}{|c|c|c|c|}
\hline & \multicolumn{3}{|c|}{ Prosthetic aortic valve stenosis* } \\
\hline & Normal & Mild stenosis & Moderate/severe stenosis \\
\hline \multicolumn{4}{|l|}{ Quantitative parameters (flow-dependent) $\dagger$} \\
\hline Peak velocity $(\mathrm{m} / \mathrm{s})$ & $<3 \mathrm{~m} / \mathrm{s}$ & $3-4 \mathrm{~m} / \mathrm{s}$ & $>4 \mathrm{~m} / \mathrm{s}$ \\
\hline Mean gradient $(\mathrm{mm} \mathrm{Hg})$ & $<20 \mathrm{~mm} \mathrm{Hg}$ & $20-40 \mathrm{~mm} \mathrm{Hg}$ & $>40 \mathrm{~mm} \mathrm{Hg}$ \\
\hline \multicolumn{4}{|l|}{ Quantitative parameters (flow-independent) } \\
\hline Doppler velocity index $\ddagger$ & $>0.35$ & $0.35-0.25$ & $<0.25$ \\
\hline Effective orifice area $\S$ & $>1.1 \mathrm{~cm}^{2}$ & $1.1-0.8 \mathrm{~cm}^{2}$ & $<0.8 \mathrm{~cm}^{2}$ \\
\hline \multirow[t]{3}{*}{ Effective orifice area $\|$} & $>0.9 \mathrm{~cm}^{2}$ & $0.9-0.6 \mathrm{~cm}^{2}$ & $<0.6 \mathrm{~cm}^{2}$ \\
\hline & \multicolumn{3}{|c|}{ Prosthesis-patient mismatch (PPM) } \\
\hline & Insignificant & Moderate & Severe \\
\hline \multirow{4}{*}{$\begin{array}{l}\text { Indexed effective orifice area } \uparrow\left(\mathrm{cm}^{2} / \mathrm{m}^{2}\right) \\
\text { Indexed effective orifice area\# }\left(\mathrm{cm}^{2} / \mathrm{m}^{2}\right)\end{array}$} & $>0.85 \mathrm{~cm}^{2} / \mathrm{m}^{2}$ & $0.85-0.65 \mathrm{~cm}^{2} / \mathrm{m}^{2}$ & $<0.65 \mathrm{~cm}^{2} / \mathrm{m}^{2}$ \\
\hline & $>0.70 \mathrm{~cm}^{2} / \mathrm{m}^{2}$ & $0.90-0.60 \mathrm{~cm}^{2} / \mathrm{m}^{2}$ & $<0.60 \mathrm{~cm}^{2} / \mathrm{m}^{2}$ \\
\hline & \multicolumn{3}{|c|}{ Prosthetic aortic valve regurgitation } \\
\hline & Mild & Moderate & Severe \\
\hline \multicolumn{4}{|l|}{ Semiquantitative parameters } \\
\hline Diastolic flow reversal in the descending aorta-PW & Absent or brief early diastolic & Intermediate & Prominent, holodiastolic \\
\hline $\begin{array}{l}\text { Circumferential extent of prosthetic valve paravalvular } \\
\text { regurgitation }(\%)^{* *}\end{array}$ & $<10 \%$ & $10 \%-29 \%$ & $\geq 30 \%$ \\
\hline \multicolumn{4}{|l|}{ Quantitative parameters $\ddagger$} \\
\hline Regurgitant volume (mL/beat) & $<30 \mathrm{~mL}$ & $30-59 \mathrm{~mL}$ & $\geq 60 \mathrm{~mL}$ \\
\hline Regurgitant fraction $(\%)$ & $<30 \%$ & $30-49 \%$ & $\geq 50 \%$ \\
\hline EROA $\left(\mathrm{cm}^{2}\right)$ & $0.10 \mathrm{~cm}^{2}$ & $0.10-0.29 \mathrm{~cm}^{2}$ & $\geq 0.30 \mathrm{~cm}^{2}$ \\
\hline
\end{tabular}

$P W$, Pulsed wave; EROA, effective regurgitant orifice area. *In conditions of normal or near normal stroke volume $(50-70 \mathrm{~mL})$. $\dagger$ These parameters are more affected by flow, including concomitant aortic regurgitation. ‡For LVOT $>2.5 \mathrm{~cm}$, significant stenosis criteria is $<0.20$. §Use in setting of BSA $\geq 1.6 \mathrm{~cm}^{2}$ (note: dependent on the size of the valve and the size of the native annulus). \|Use in setting of BSA $<1.6 \mathrm{~cm}^{2}$. .Use in setting of BMI $<30 \mathrm{~kg} / \mathrm{cm}^{2}$. \#Use in setting of BMI $\geq 30 \mathrm{~kg} / \mathrm{cm}^{2}$. **Not well-validated and may overestimate the severity compared with the quantitative Doppler.

implantation, 1 year following implantation, and yearly thereafter. At these endpoints, prosthetic aortic valve stenosis and regurgitation should be reported.

\section{Transcatheter Valve Stenosis}

The assessment of prosthetic valve stenosis should be an integrative process utilizing multiple parameters of valve function. Table 10 outlines the primary parameters used for assessing prosthetic valve function based on published guidelines. ${ }^{40}$ Divergence from the guidelines is based on a number of studies, ${ }^{41,42}$ as well as methods used in large randomized control trials of TAVI. ${ }^{43,44}$ In addition, VARC-2 does not recommend using acceleration time, which is dependent on ventricular function and heart rate. ${ }^{42}$ The limitation of flow-dependent parameters such as peak jet velocity or mean transprosthetic gradient is obvious, however, even flow-independent parameters such as the effective orifice area (EOA) and the Doppler velocity index (DVI) have limitations: (i) the absolute EOA does not account for the cardiac output requirements in relation to the patient's body size; thus lower criteria should be used to define prosthetic valve stenosis in patients with BSA $<1.6 \mathrm{~m}^{2}$ (Table 10), (ii) the indexed EOA may overestimate the valve-related hemodynamic burden in obesity; hence, lower criteria may be more appropriate in patients with a body mass index $\geq 30 \mathrm{~kg} / \mathrm{m}^{2}$, (iii) DVI severity criteria are dependent on the left ventricular outflow tract (LVOT) size; thus a lower threshold may be more appropriate in patients with LVOT diameters of $>25 \mathrm{~mm}$. The EOA should generally be calculated with the use of the LVOT diameter and the velocity measured just underneath the apical margin of the valve stent. ${ }^{45,46}$ In cases where the landing zone of the stent is low in the LVOT, the diameter and velocity may both be measured in the proximal portion of the stent. Unlike the surgically implanted valve, the transcatheter prosthetic valve EOA is defined not only by the size of the valve but also by the patient's aortic valve/annular anatomy and procedural variables. Thus, well-established normal transcatheter valve gradients and EOAs based on preimplant aortic annular dimensions do not currently exist. Clinicians should be aware of this variability when assessing a patient for transcatheter valve function and VARC-2 strongly recommends that the patient's own initial postimplant study be used as a reference for serial comparisons.

The assessment of transcatheter valve dysfunction includes the immediate post-TAVI hemodynamics and the 


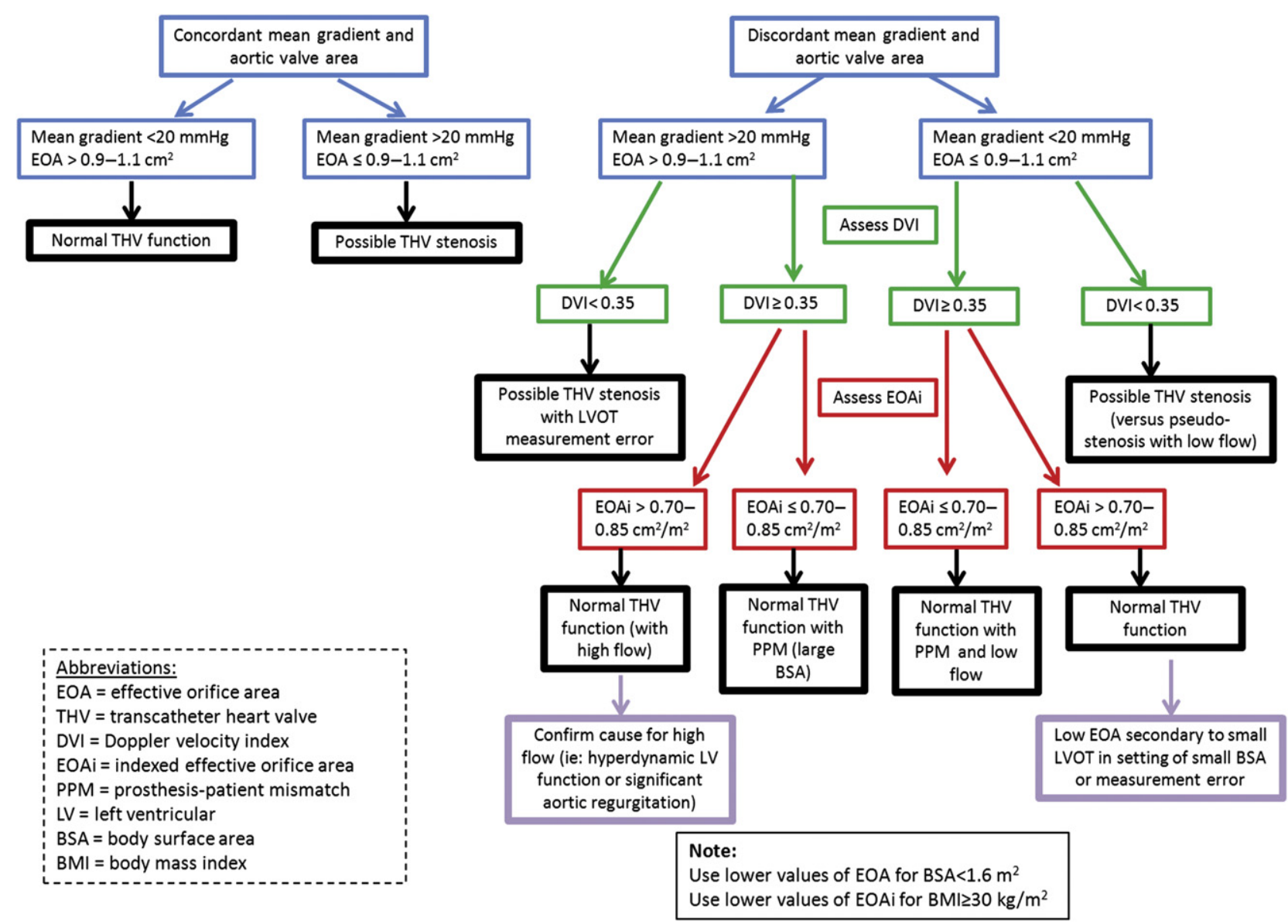

FIGURE 4. Transcatheter heart valve hemodynamic evaluation algorithm.

follow-up evaluation. The immediate post-TAVI evaluation documents initial valve appearance (position and circularity of the stent, and leaflet morphology and motion) and a comprehensive hemodynamic evaluation. Valve Academic Research Consortium-2 advocates using the integrative approach outlined in the algorithm shown in Figure 4 as part of a comprehensive hemodynamic evaluation by using 1 flow dependent (eg, mean gradient) and 1 flow independent criterion (eg, EOA) for the initial hemodynamic evaluation. If there is discordance between these measurements, then the DVI should be calculated. An abnormal DVI indicates possible prosthetic valve dysfunction. A normal DVI indicates intrinsically normal prosthetic valve function, and the indexed EOA can then be used to determine the reason for the initial measurement discordance. When the indexed EOA is low in the setting of a normal DVI, the patient probably has a prosthesis-patient mismatch (PPM), an indicator of the intrinsic relationship of the implanted valve to the cardiac output requirements of the patient. ${ }^{47}$ Prosthesis-patient mismatch occurs in the setting of a morphologically normal valve and is considered to be hemodynamically insignificant if the indexed EOA is $>0.85 \mathrm{~cm}^{2} / \mathrm{m}^{2}$, moderate if between
0.65 and $0.85 \mathrm{~cm}^{2} / \mathrm{m}^{2}$, and severe if $<0.65 \mathrm{~cm}^{2} / \mathrm{m}^{2}$. However, for obese patients (body mass index $\geq 30 \mathrm{~kg} / \mathrm{m}^{2}$ ) lower criteria may be more appropriate (Table 10).

\section{Transcatheter Valve Regurgitation}

There is growing evidence suggesting a significant association of postprocedural paravalvular aortic regurgitation (AR) with short- and long-term mortality. ${ }^{48,49}$ As the duration of implanted transcatheter heart valves increases, valve durability and dysfunction become more crucial issues. Evaluating the presence and severity of regurgitation should include an assessment of both central and paravalvular components, with a combined measurement of "total" aortic regurgitation (AR) reflecting the total volume load imposed on the LV (Table 10). The quantitative and semiquantitative hemodynamic assessment of AR severity should be performed with Doppler echocardiography according to the guidelines. ${ }^{39,50,51}$ Color Doppler evaluation should be performed just below the valve stent for paravalvular jets, and at the coaptation point of the leaflets for central regurgitation. Although all imaging windows should be used, the parasternal short-axis view is critical in assessing the number and 
severity of paravalvular jets. Whenever possible, the quantification of the prosthetic regurgitant volume, effective regurgitant orifice area, and regurgitant fraction (Table 10) should be performed. ${ }^{40,51,52}$ The regurgitant volume may be calculated as the difference between the stroke volume across any nonregurgitant orifice (RVOT or mitral valve) and the stroke volume across the LVOT.

It is important to realize that at this time the body of evidence supporting the numerical criteria used in Table 10 as well as Figure 4 may be limited. These criteria should be used as guidelines for clinical decision-making and require further validation as our experience continues to expand.

\section{Follow-up Assessments}

The follow-up assessment should also begin with valve imaging and documentation of changes in morphology. When determining whether a patient has developed hemodynamically significant structural valve failure, the patient's own baseline echocardiographic parameters should be used as a reference. An increase in the mean gradient $>10 \mathrm{~mm} \mathrm{Hg}$, a decrease in the EOA $>0.3-0.4 \mathrm{~cm}^{2}$, or a reduction in the DVI $>0.1-0.13$ probably indicates a change in valve function and should trigger a comprehensive hemodynamic evaluation. Whenever valve dysfunction is suspected, the careful evaluation of valve morphology should confirm a structurally abnormal valve. In addition, measurement error must be excluded; the use of a consistent LVOT diameter for more accurate follow-up study comparisons is recommended. Finally, changes in ventricular morphology would be expected in the setting of long-standing significant valvular dysfunction and this parameter may support the clinical assessment of severity.

Although the rate of moderate or severe regurgitation may appear to be less at the follow-up, this may be the result of attrition of the sickest patients. To assess such time trends, it is recommended to report an individual patient's progression of regurgitation, in a table that provides changes between short-term and long-term regurgitation, including mortality. ${ }^{48}$

\section{QUALITY OF LIFE}

\section{Quality of Life Evaluation in Aortic Stenosis}

New York Heart Association (NYHA) classification is limited by the discrete nature of the scale, which provides only modest resolution to detect clinically relevant changes. Moreover, since the NYHA class is assessed by an external body rather than the patient, it does not reflect the patient's perspective. Thus, the NYHA class is more properly considered a measure of the functional status than the QOL.

The Minnesota Living with Heart Failure Questionnaire $(\mathrm{MLHF})^{53}$ and the Kansas City Cardiomyopathy Questionnaire $(\mathrm{KCCQ})^{54,55}$ have a number of desirable properties for the evaluation of health-related QOL (HRQOL) in the setting of AS. Both instruments produce outcomes on a continuous scale, which improves responsiveness and sensitivity. Although only the MLHF has been specifically validated in patients with aortic valve disease,${ }^{56}$ preliminary experience with the KCCQ in patients undergoing TAVI has also demonstrated a high degree of responsiveness and internal consistency. ${ }^{57}$

\section{Recommended Endpoints and Timing of Assessment}

Valve Academic Research Consortium-2 recommends that a comprehensive assessment of HRQOL for patients undergoing TAVI incorporate both a heart failure-specific measure (such as the KCCQ or MLHF) as well as 1 or more generic measures (such as the Medical Outcomes Study Short-Form 36 [SF-36], the Short-Form 12 [SF-12], or the EuroQOL [EQ-5D]). ${ }^{58-60}$ The disease-specific measures offer improved sensitivity/responsiveness as well as clinical interpretability, whereas the inclusion of a generic health status measure is useful because it captures some additional domains. Furthermore, generic measures can enhance the comparability across different diseases and populations and can be used to compare patients with population-level benchmarks.

For the comparison of TAVI versus SAVR (or for the comparison of alternative access sites for TAVI), we recommend that early QOL assessment be performed at 2 weeks, 1 month, and 3 months using a combination of generic instruments and pain scales (eg, visual analogue scale) to assess the early recovery process. The evaluation of the QOL at an intermediate time point (eg, 6 months) could also be considered in order to confirm that QOL recovery is complete by this stage. At later time points (1-5 years), the use of heart failure-specific instruments to identify the consequences of long-term valve performance may be more useful. Finally, the assessment of cognitive function at later time points (1-5 years) may be valuable for the comparison of surgical versus catheter-based techniques, although these endpoints generally require highly specialized and demanding neuropsychiatric testing. ${ }^{61}$ In contrast, for the comparison of alternative TAVI systems (as may be expected in the near future), HRQOL assessment should focus mainly on heart failure-specific endpoints at intermediate and later time points (1-5 years), wherein between-device differences in the hemodynamic performance or structural valve deterioration may emerge. The inclusion of disease-specific QOL measures in these studies can also provide insight into the consequences of valve-related complications such as the need for pacemaker insertion.

\section{Additional Considerations}

It is essential to ensure complete ascertainment of HRQOL at each time point, as missing data cannot be retrieved retrospectively and statistical adjustment techniques (eg, multiple imputation) that assume that data are "missing at random" may not be adequate. Differential mortality 
between 2 treatments may complicate the interpretation of QOL results since the QOL may appear to "improve" over time even with an ineffective therapy simply because of attrition of the sickest patients. The use of categorical endpoints that characterize outcomes as favorable (eg, survival AND improvement of QOL endpoints) ${ }^{44,57}$ or endpoints that integrate survival and the QOL (eg, quality-adjusted life expectancy) may provide more interpretable results. In such cases, reporting the outcomes in both ways (ie, among the entire study cohort and separately among only the surviving patients) will provide the most complete description of the results.

\section{COMPOSITE ENDPOINTS \\ Rationale and Caveats}

Comparisons of the success, safety, and effectiveness with achievable study cohort sample sizes may at times require the use of composite endpoints. However, it is important that composites contain components that have roughly similar impacts on the patient. A family of single endpoints tending in the same direction may, as a family of hypotheses, be statistically significant when individual endpoints are not.

Each postprocedural event has a different temporal risk profile (hazard function) modulated by different risk factors. Therefore, traditionally, the evaluation of the safety and efficacy of procedures has focused on in-hospital events (complications and morbidity), events within 30 days of the procedure, and "late" events.

\section{Specific Composite Endpoints}

The assessment of TAVI, SAVR, and their alternatives or new devices should include device, procedure, and patientoriented endpoints. These endpoints have been devised to be applicable to both TAVI and SAVR. Previous clinical trials have used the all-cause mortality at 1 year as the primary clinical endpoint. Owing to the emergence of stroke as an important clinical event, future trials should also require the composite of all-cause mortality and disabling stroke as a primary or secondary endpoint.

The first VARC document proposed 3 composite endpoints: device success, early safety, and clinical efficacy. Valve Academic Research Consortium-2 goes beyond the early and intermediate experience of TAVI, drawing upon prior surgical AVR guidelines to include time-related safety endpoints. ${ }^{62}$ Therefore, VARC-2 recommends a new composite endpoint, time-related valve safety, which combines valve dysfunction, endocarditis, and thrombotic complications of the prosthesis (Table 11).

\section{DISCUSSION}

Although the original VARC standardized endpoint definitions were fundamentally useful and have been widely adopted, growing experience with TAVI studies has identified some definitions as ambiguous, of limited clinical
TABLE 11. Composite endpoints

Device success

Absence of procedural mortality AND

Correct positioning of a single prosthetic heart valve into the proper anatomical location AND

Intended performance of the prosthetic heart valve (no prosthesispatient mismatch* and mean aortic valve gradient $<20 \mathrm{~mm} \mathrm{Hg}$ or peak velocity $<3 \mathrm{~m} / \mathrm{s}$, AND no moderate or severe prosthetic valve regurgitation*)

Early safety (at 30 days)

All-cause mortality

All stroke (disabling and nondisabling)

Life-threatening bleeding

Acute kidney injury-Stage 2 or 3 (including renal replacement therapy)

Coronary artery obstruction requiring intervention

Major vascular complication

Valve-related dysfunction requiring repeat procedure (BAV, TAVI, or SAVR)

Clinical efficacy (after 30 days)

All-cause mortality

All stroke (disabling and nondisabling)

Requiring hospitalizations for valve-related symptoms or worsening congestive heart failure $\dagger$

NYHA class III or IV

Valve-related dysfunction (mean aortic valve gradient $\geq 20 \mathrm{~mm} \mathrm{Hg}$, EOA $\leq 0.9-1.1 \mathrm{~cm}^{2} \ddagger$ and/or DVI $<0.35 \mathrm{~m} / \mathrm{s}$, AND/OR moderate or severe prosthetic valve regurgitation*)

Time-related valve safety

Structural valve deterioration

Valve-related dysfunction (mean aortic valve gradient $\geq 20 \mathrm{~mm} \mathrm{Hg}$, EOA $\leq 0.9-1.1 \mathrm{~cm}^{2} \ddagger$ and/or DVI $<0.35 \mathrm{~m} / \mathrm{s}$, AND/OR moderate or severe prosthetic valve regurgitation*)

Requiring repeat procedure (TAVI or SAVR)

Prosthetic valve endocarditis

Prosthetic valve thrombosis

Thrombo-embolic events (eg, stroke)

VARC bleeding, unless clearly unrelated to valve therapy (eg, trauma) $B A V$, Balloon aortic valvuloplasty; $T A V I$, transcatheter aortic valve implantation; $S A V R$, surgical aortic valve replacement. *Refers to VARC definitions. $\dagger$ As a basis for calculation of "days alive outside the hospital" endpoint. Supplementary appendix of Leon et al. ${ }^{43}$ Includes heart failure, angina, or syncope due to aortic valve disease requiring intervention or intensified medical management; clinical symptoms of CHF with objective signs including pulmonary edema, hypoperfusion, or documented volume overload AND administration of IV diuresis or inotropic therapy, performance of aortic valvuloplasty, institution of mechanical support (IABP or ventilation for pulmonary edema) or hemodialysis for volume overload; clear documentation of anginal symptoms AND no clinical evidence that angina was related to CAD or ACS; documented loss of consciousness not related to seizure or tachyarrhythmia. †ॄDepending on the body surface area.

utility, or in need of updating or extension. ${ }^{5,6,63,64}$ This need provided the rationale for a VARC-2 document with such improvements and additions. As was the case with the original VARC process, it should be emphasized that this consensus manuscript is not intended to be a guidelines document, but rather a practical tool to facilitate and inform clinical research in TAVI. 
Current clinical trials are focusing more on intermediate risk patients, and more studies are comparing TAVI with surgical AVR. Therefore, it becomes increasingly important to identify those patients who benefit from either treatment. Specific risk categories have been defined to allow universal clinical study designs and outcome comparisons.

Changes and additions that have been applied to improve the interpretation of clinical endpoint definitions and provide further insights on TAVI-related outcomes are as follows: (i) risk stratification should be done by a dedicated "heart team" and include other factors (eg, frailty, porcelain aorta) beyond the traditional risk scores, and should take into account coexisting conditions; (ii) immediate procedural death has been added to capture intraprocedural events that result in immediate or consequent death; (iii) stroke ascertainment requires the use of precise definitions, standardized assessments, close collaboration with neurology experts including the consideration of acute stroke management, and has been recategorized as nondisabling or disabling; (iv) detailed documentation of the etiology of strokes and concomitant therapies is needed to provide insights into the multi-factorial nature of acute, early, and late strokes; (v) closure device failure is now a separate category within vascular complications, and if unplanned percutaneous or surgical intervention does not lead to adverse outcomes, these are not considered as a major vascular complication per se; (vi) the time for AKI diagnosis has been extended from $72 \mathrm{~h}$ to 7 days; (vii) AKI is diagnosed according to AKIN guidelines, which include classification by the urine output to detect a wider range of etiologies; (viii) periprocedural myocardial infarction is defined by troponin or CK-MB elevation and the troponin threshold has changed from $10 \times$ ULN to $15 \times$ ULN based on recent data ${ }^{19}$; (ix) assessment of conduction disturbances and arrhythmias has been reinforced ${ }^{65-68}$; (x) new definitions for several TAVI-related complications and valve malpositioning are reported; (xi) echocardiography parameters of prosthetic valve stenosis and regurgitation have been updated and now include the assessment of the prosthesis-patient mismatch; (xii) for the QOL assessment, VARC-2 recommends the use of both heart failure-specific and generic measures during the follow-up between 30 days and 5 years to fully assess the impact of the procedure and the durability of clinical benefit. These definitions can be used in studies comparing TAVI to surgical AVR, as well as in future trials comparing first generation to next generation TAVI devices.

The composite endpoint of device success has specifically been criticized for being too strict with regard to valve performance; for example, an AVA $>1.2 \mathrm{~cm}^{2}$ seems unachievable in patients with smaller body habitus. ${ }^{5}$ The current VARC-2 definition therefore corrects for the body surface area so that valve performance is now assessed through the indexed EOA. It is notable that valve-in-valve procedures for failing bioprostheses will frequently have a low device success, even with this modified definition. ${ }^{69}$ Considering that stroke has emerged as an important concern, the composite of all-cause mortality and disabling stroke should be considered as a primary or secondary endpoint in future trials. Two ongoing large randomized trials (PARTNER II [NCT01314313] and SURTAVI [NCT01586910]) are already incorporating these composite endpoints.

With longer follow-up duration, it becomes more critical to include time-related valve safety composite endpoints. This will eventually provide linearized rates of complications with transcatheter valves, known as "objective performance criteria," as has been used to evaluate surgical valves. ${ }^{70}$

With this VARC-2 document, we have provided further standardization of endpoint definitions and hope that the adoption of these criteria will continue to increase, ultimately leading to improved comparability and interpretability of the study results.

\section{Funding}

Grants have been provided to the ARC Board including representatives of Cardialysis, the Cardiovascular Research Foundation, Duke Clinical Research Institute, and Harvard Clinical Research Institute to cover the costs of travel, meeting rooms, and lodging for academic attendees at the Washington and Rotterdam meetings by Abbott Vascular, Boston Scientific, Direct Flow Medical, Edwards Lifesciences, Heart Leaflet Technologies, Medtronic Corporation, and St. Jude Medical.

Conflict of interest: VARC Participants will provide Conflict of Interest Disclosures individually prior to publication. The VARC meetings involved members of the Interventional Cardiology Devices Branch, of the Office of Device Evaluation, Center for Devices and Radiological Health, USFDA. The opinions or assertions herein are the private views of the authors and are not to be construed as reflecting the views of the FDA.

\section{APPENDIX 1}

VARC contributing groups

(1) Academic Research Organizations

Cardialysis (Rotterdam, The Netherlands)

Cardiovascular Research Foundation (New York, NY)

Duke Clinical Research Institute (Durham, NC) Harvard Clinical Research Institute (Boston, Mass)

(2) Societies

American College of Cardiology European Association for CardioThoracic Surgery European Society of Cardiology

Society of Thoracic Surgeons

(3) US Food and Drug Administration

(4) Industry representatives 


\section{APPENDIX 2}

VARC participants

(1) Clinical Research Organizations

(i) Cardialysis/Erasmus MC, Rotterdam, The Netherlands

Head, SJ

Morel, MA

Serruys, PW

Van Es, GA

Van Mieghem, NM

Vranckx, P

(ii) Cardiovascular Research Foundation, New York, NY

Généreux, $\mathrm{P}$

Hahn, RT

Kirtane, AJ

Kodali, SK

Leon, MB

Maxwell, Y

Mehran, R

(iii) Duke Clinical Research Institute, Durham, NC

Alexander, KP

Douglas, DS

Krucoff, MW

Petersen, J

(iv) Harvard Cardiovascular Research Institute, Boston, Mass

\section{Cutlip, DE}

(2) Cardiologists

Borer, JS: Howard Gilman Institute for Heart Valve Diseases, Brooklyn, NY

Cohen, DJ: Saint Luke's Mid America Heart Institute,

Kansas City, Mo

Holmes, DR Jr: Mayo Clinic Rochester, Rochester, Minn

Iung, B: CHU Bichat, Paris, France

Makkar, RR: Cedars-Sinai Heart Institute, Los Angeles, Calif

Piazza, N: German Heart Center, Munich, Germany; and McGill University Health Center, Montral, Canada

Popma, JJ: Beth Israel-Deaconess Medical Center, Boston, Mass

Rodès-Cabau, J: Quebec Heart and Lung Institute, Quebec, Canada

Thomas, M: Guys and St Thomas Hospital, London, UK

Tuzcu, EM: Cleveland Clinic Foundation, Cleveland, Ohio

Vahanian, A: CHU Bichat, Paris, France
Webb, JG: St Paul's Hospital, Vancouver, BC, Canada

Windecker, S: University Hospital Bern, Bern, Switzerland

(3) Surgeons

Adams, DH: Mount Sinai Medical Center, New York, NY

Cameron, DE: The Johns Hopkins Medical Institutions, Baltimore, $\mathrm{Md}$

Fontana, GP: Lenox Hill Heart and Vascular Institute, New York, NY

Kappetein, AP: Erasmus MC, Rotterdam, The Netherlands

Mack, MJ: Baylor Health Care Systems, Tex

Maisano, F: San Raffaele Hospital, Milan, Italy

Miller, DC: Stanford University, Calif

Moat, NE: Royal Brompton and Harefield National Health Service (NHS) Foundation Trust, London, UK Walther, T: Kerckhoff Heartcenter Bad Nauheim, Bad Nauheim, Germany

(4) Echocardiographers

Geleijnse, ML: Erasmus University Medical Center, Rotterdam, The Netherlands

(5) Neurologists

Brott, TG: Mayo Clinic, Jacksonville, Fla

Van der Worp, HB: University Medical Center Utrecht, Utrecht, The Netherlands

(6) Statisticians

Blackstone, EH: Cleveland Clinic Foundation, Cleveland, Ohio

(7) US Food and Drug Administration

Aguel, F

Dunn, B

Getzoff, N

Laschinger, $\mathrm{J}$

Patel, S

Sansing, V

Sastry, A

Swain, J

Zuckerman, B

(8) Industry representatives

Akin, J: Edwards Lifesciences, Orange, Calif

Allocco, D: Boston Scientific, Minneapolis, Minn

Armitage, T: Medtronic CardioVascular, Minneapolis, Minn

Bebeau, V: St Jude Medical, Minneapolis, Minn

Concepcion, B: Boston Scientific, Minneapolis, Minn 
Fonseca, T: Medtronic CardioVascular, Minneapolis, Minn

Robb, R: Medtronic CardioVascular, Minneapolis, Minn

Schroeder R: Heart Leaflet Technologies, Minneapolis, Minn

Sethuraman, B: Abbott Vascular, Santa Clara, Calif Sheahan, B: Direct Flow Medical, Santa Rosa, Calif Tatarek, N: St Jude Medical, Minneapolis, Minn

(9) Observers: other

Fitzgerald, S

Carroll, JD

Edwards, FH

Lansky, AJ

Prager, RL

\section{References}

1. Leon MB, Piazza N, Nikolsky E, Blackstone EH, Cutlip DE, Kappetein AP, et al. Standardized endpoint definitions for Transcatheter Aortic Valve Implantation clinical trials: a consensus report from the Valve Academic Research Consortium. J Am Coll Cardiol. 2011;57:253-69.

2. Leon MB, Piazza N, Nikolsky E, Blackstone EH, Cutlip DE, Kappetein AP, et al. Standardized endpoint definitions for transcatheter aortic valve implantation clinical trials: a consensus report from the Valve Academic Research Consortium. Eur Heart J. 2011;32:205-17.

3. Généreux P, Head SJ, Van Mieghem NM, Kodali S, Kirtane AJ, Xu K, et al. Clinical outcomes after transcatheter aortic valve replacement using Valve Academic Research Consortium definitions: a weighted meta-analysis of 3,519 patients from 16 studies. J Am Coll Cardiol. 2012;59:2317-26.

4. Clavel MA, Rodes-Cabau J, Dumont E, Bagur R, Bergeron S, De Larochelliere R, et al. Validation and characterization of transcatheter aortic valve effective orifice area measured by Doppler echocardiography. JACC Cardiovasc Imaging. 2011;4:1053-62.

5. Ikeda K, Ho M, Kawahara M. Valve academic research consortium consensus report the pharmaceutical and medical devices agency perspective. J Am Coll Cardiol. 2011;58:777.

6. Gurvitch R, Toggweiler S, Willson AB, Wijesinghe N, Cheung A, Wood DA, et al. Outcomes and complications of transcatheter aortic valve replacement using a balloon expandable valve according to the Valve Academic Research Consortium (VARC) guidelines. EuroIntervention. 2011;7:41-8.

7. Delgado V, Schuijf JD, Bax JJ. Pre-operative aortic valve implantation evaluation: multimodality imaging. EuroIntervention. 2010;6:G38-47.

8. Piazza N, Wenaweser P, van Gameren M, Pilgrim T, Tzikas A, Otten A, et al. Relationship between the logistic EuroSCORE and the Society of Thoracic Surgeons Predicted Risk of Mortality score in patients implanted with the CoreValve ReValving system-a Bern-Rotterdam Study. Am Heart J. 2010; 159:323-9.

9. Rosenhek R, Iung B, Tornos P, Antunes MJ, Prendergast BD, Otto CM, et al. ESC Working Group on Valvular Heart Disease Position Paper: assessing the risk of interventions in patients with valvular heart disease. Eur Heart J. 2012;33:822-8.

10. Afilalo J, Mottillo S, Eisenberg MJ, Alexander KP, Noiseux N, Perrault LP, et al. Addition of frailty and disability to cardiac surgery risk scores identifies elderly patients at high risk of mortality or major morbidity. Circ Cardiovasc Qual Outcomes. 2012;5:222-8.

11. Pal SK, Katheria V, Hurria A. Evaluating the older patient with cancer: understanding frailty and the geriatric assessment. CA Cancer J Clin. 2010;60:120-32.

12. Morris JC. The clinical dementia rating (CDR): current version and scoring rules. Neurology. 1993;43:2412-4.

13. Mack DR Jr, Holmes MJ, Kaul S, Agnihotri A, Alexander KP, Bailey SR, et al. 2012 ACCF/AATS/SCAI/STS expert consensus document on transcatheter aortic valve replacement: developed in collaboration with the American Heart Association, American Society of Echocardiography, European Association for Cardio-Thoracic Surgery, Heart Failure Society of America, Mended Hearts,
Society of Cardiovascular Anesthesiologists, Society of Cardiovascular Computed Tomography, and Society for Cardiovascular Magnetic Resonance. Ann Thorac Surg. 2012;93:1340-95.

14. Yourman LC, Lee SJ, Schonberg MA, Widera EW, Smith AK. Prognostic indices for older adults: a systematic review. JAMA. 2012;307:182-92.

15. Sianos G, Morel MA, Kappetein AP, Morice MC, Colombo A, Dawkins K, et al The SYNTAX Score: an angiographic tool grading the complexity of coronary artery disease. EuroIntervention. 2005;1:219-27.

16. Serruys PW, Morice MC, Kappetein AP, Colombo A, Holmes DR, Mack MJ, et al. Percutaneous coronary intervention versus coronary-artery bypass grafting for severe coronary artery disease. N Engl J Med. 2009;360:961-72.

17. Dewey TM, Brown DL, Herbert MA, Culica D, Smith CR, Leon MB, et al. Effect of concomitant coronary artery disease on procedural and late outcomes of transcatheter aortic valve implantation. Ann Thorac Surg. 2010;89:758-67; discussion 767.

18. Wenaweser P, Pilgrim T, Guerios E, Stortecky S, Huber C, Khattab AA, et al. Impact of coronary artery disease and percutaneous coronary intervention on outcomes in patients with severe aortic stenosis undergoing transcatheter aortic valve implantation. EuroIntervention. 2011;7:541-8.

19. Rodes-Cabau J, Gutierrez M, Bagur R, De Larochelliere R, Doyle D, Cote M, et al. Incidence, predictive factors, and prognostic value of myocardial injury following uncomplicated transcatheter aortic valve implantation. J Am Coll Cardiol. 2011;57:1988-99.

20. Thygesen K, Alpert JS, White HD, Joint ESC/ACCF/AHA/WHF Task Force for the Redefinition of Myocardial Infarction. Universal definition of myocardial infarction. Eur Heart J. 2007;28:2525-38.

21. Daneault B, Kirtane AJ, Kodali SK, Williams MR, Genereux P, Reiss GR, et al Stroke associated with surgical and transcatheter treatment of aortic stenosis: a comprehensive review. J Am Coll Cardiol. 2011;58:2143-50.

22. Standardized Definitions for Cardiovascular Outcomes Trials: FDA Draft Recommendations (personal communication; 24 March 2010).

23. Brott T, Olinger HP Jr, Adams CP, Marler JR, Barsan WG, Biller J, et al. Measurements of acute cerebral infarction: a clinical examination scale. Stroke. 1989;20:864-70.

24. Bonita R, Beaglehole R. Recovery of motor function after stroke. Stroke. 1988; 19:1497-500.

25. Lyden PD, Lau GT. A critical-appraisal of stroke evaluation and rating-scales Stroke. 1991;22:1345-52.

26. Wintermark M, Albers GW, Alexandrov AV, Alger JR, Bammer R, Baron JC, et al. Acute stroke imaging research roadmap. Stroke. 2008;39:1621-8.

27. Miller DC, Blackstone EH, Mack MJ, Svensson LG, Kodali SK, Kapadia S, et al., The PARTNER Trial Investigators and Patients, The PARTNER Stroke Substudy Writing Group Executive Committee. Transcatheter (TAVR) versus surgical (AVR) aortic valve replacement: Occurrence, hazard, risk factors, and consequences of neurologic events in the PARTNER trial. $J$ Thorac Cardiovasc Surg. 2012;143:832-43. e13.

28. Ndrepepa G, Schuster T, Hadamitzky M, Byrne RA, Mehilli J, Neumann FJ, et al. Validation of the bleeding academic research consortium definition of bleeding in patients with coronary artery disease undergoing percutaneous coronary intervention. Circulation. 2012;125:1424-31.

29. Mehran R, Rao SV, Bhatt DL, Gibson CM, Caixeta A, Eikelboom J, et al. Standardized bleeding definitions for cardiovascular clinical trials: a consensus report from the Bleeding Academic Research Consortium. Circulation. 2011;123: 2736-47.

30. Ussia GP, Barbanti M, Petronio AS, Tarantini G, Ettori F, Colombo A, et al., CoreValve Italian Registry Investigators. Transcatheter aortic valve implantation: 3 year outcomes of self-expanding CoreValve prosthesis. Eur Heart J. 2012;33: 969-76.

31. Mehta RL, Kellum JA, Shah SV, Molitoris BA, Ronco C, Warnock DG, Levin A, Acute Kidney Injury N. Acute Kidney Injury Network: report of an initiative to improve outcomes in acute kidney injury. Crit Care. 2007;11:R31.

32. Kidney Disease: Improving Global Outcomes (KDIGO) Acute Kidney Injury Work Group. KDIGO Clinical Practice Guideline for Acute Kidney Injury. Kidney int Suppl. 2012;2:1-138.

33. Genereux P, Kodali S, Leon MB, Smith CR, Ben-Gal Y, Kirtane AJ, et al. Clinica outcomes using a new crossover balloon occlusion technique for percutaneous closure after transfemoral aortic valve implantation. JACC Cardiovasc Interv. 2011;4:861-7.

34. Sharp AS, Michev I, Maisano F, Taramasso M, Godino C, Latib A, et al. A new technique for vascular access management in transcatheter aortic valve implantation. Catheter Cardiovasc Interv. 2010;75:784-93. 
35. Camm AJ, Kirchhof P, Lip GY, Schotten U, Savelieva I, Ernst S, et al., European Heart Rhythm Association, European Association for Cardio-Thoracic Surgery. Guidelines for the management of atrial fibrillation: the Task Force for the Management of Atrial Fibrillation of the European Society of Cardiology (ESC). Eur Heart J. 2010;31:2369-429.

36. Al Ali AM, Altwegg L, Horlick EM, Feindel C, Thompson CR, Cheung A, et al. Prevention and management of transcatheter balloon-expandable aortic valve malposition. Catheter Cardiovasc Interv. 2008;72:573-8.

37. Geisbusch S, Bleiziffer S, Mazzitelli D, Ruge H, Bauernschmitt R, Lange R. Incidence and management of CoreValve dislocation during transcatheter aortic valve implantation. Circ Cardiovasc Interv. 2010;3:531-6.

38. Gerckens U, Latsios G, Mueller R, Buellesfeld L, John D, Yuecel S, et al. Procedural and mid-term results in patients with aortic stenosis treated with implantation of 2 (in-series) CoreValve prostheses in 1 procedure. JACC Cardiovasc Interv. 2010;3:244-50.

39. Bonow RO, Carabello BA, Chatterjee K, Faxon AC Jr, de Leon DP, Freed MD, et al., American College of Cardiology/American Heart Association Task Force on Practice Guidelines. 2008 focused update incorporated into the ACC/AHA 2006 guidelines for the management of patients with valvular heart disease: a report of the American College of Cardiology/American Heart Association Task Force on Practice Guidelines (Writing Committee to revise the 1998 guidelines for the management of patients with valvular heart disease). Endorsed by the Society of Cardiovascular Anesthesiologists, Society for Cardiovascular Angiography and Interventions, and Society of Thoracic Surgeons. J Am Coll Cardiol. 2008;52:e1-142.

40. Zoghbi WA, Chambers JB, Dumesnil JG, Foster E, Gottdiener JS, Grayburn PA, et al. Recommendations for evaluation of prosthetic valves with echocardiography and Doppler ultrasound: a report From the American Society of Echocardiography's Guidelines and Standards Committee and the Task Force on Prosthetic Valves, developed in conjunction with the American College of Cardiology Cardiovascular Imaging Committee, Cardiac Imaging Committee of the American Heart Association, the European Association of Echocardiography, a registered branch of the European Society of Cardiology, the Japanese Society of Echocardiography and the Canadian Society of Echocardiography, endorsed by the American College of Cardiology Foundation, American Heart Association, European Association of Echocardiography, a registered branch of the European Society of Cardiology, the Japanese Society of Echocardiography, and Canadian Society of Echocardiography. J Am Soc Echocardiogr. 2009;22: 975-1014, quiz 1082-4.

41. Rothbart RM, Castriz JL, Harding LV, Russo CD, Teague SM. Determination of aortic valve area by two-dimensional and Doppler echocardiography in patients with normal and stenotic bioprosthetic valves. J Am Coll Cardiol. 1990;15: 817-24.

42. Ben Zekry S, Saad RM, Ozkan M, Al Shahid MS, Pepi M, Muratori M, et al. Flow acceleration time and ratio of acceleration time to ejection time for prosthetic aortic valve function. JACC Cardiovasc Imaging. 2011;4:1161-70.

43. Leon MB, Smith CR, Mack M, Miller DC, Moses JW, Svensson LG, et al., PARTNER Trial Investigators. Transcatheter aortic-valve implantation for aortic stenosis in patients who cannot undergo surgery. $N$ Engl J Med. 2010;363: 1597-607.

44. Smith CR, Leon MB, Mack MJ, Miller DC, Moses JW, Svensson LG, et al., PARTNER Trial Investigators. Transcatheter versus surgical aortic-valve replacement in high-risk patients. N Engl J Med. 2011;364:2187-98.

45. Clavel MA, Webb JG, Pibarot P, Altwegg L, Dumont E, Thompson C, et al. Comparison of the hemodynamic performance of percutaneous and surgical bioprostheses for the treatment of severe aortic stenosis. J Am Coll Cardiol. 2009;53: 1883-91.

46. Shames S, Koczo A, Hahn R, Jin Z, Picard MH, Gillam LD. Flow characteristics of the SAPIEN aortic valve: The importance of recognizing in-stent flow acceleration for the echocardiographic assessment of valve function. J Am Soc Echocardiogr. 2012;25:603-9.

47. Head SJ, Mokhles MM, Osnabrugge RL, Pibarot P, Mack MJ, Takkenberg JJ, et al. The impact of prosthesis-patient mismatch on long-term survival after aortic valve replacement: a systematic review and meta-analysis of 34 observational studies comprising 27186 patients with 133141 patient-years. Eur Heart J. 2012;33:1518-29.

48. Kodali SK, Williams MR, Smith CR, Svensson LG, Webb JG, Makkar RR, et al. Two-year outcomes after transcatheter or surgical aortic-valve replacement. N Engl J Med. 2012;366:1686-95.

49. Tamburino C, Capodanno D, Ramondo A, Petronio AS, Ettori F, Santoro G, et al. Incidence and predictors of early and late mortality after transcatheter aortic valve implantation in 663 patients with severe aortic stenosis. Circulation. 2011;123:299-308.

50. Vahanian A, Baumgartner H, Bax J, Butchart E, Dion R, Filippatos G, et al., Task Force on the Management of Valvular Hearth Disease of the European Society of Cardiology, E. S. C. Committee for Practice Guidelines. Guidelines on the management of valvular heart disease: The Task Force on the Management of Valvular Heart Disease of the European Society of Cardiology. Eur Heart J. 2007;28: 230-68.

51. Zamorano JL, Badano LP, Bruce C, Chan KL, Goncalves A, Hahn RT, et al. EAE/ ASE recommendations for the use of echocardiography in new transcatheter interventions for valvular heart disease. Eur Heart J. 2011;32:2189-214.

52. Zoghbi WA, Enriquez-Sarano M, Foster E, Grayburn PA, Kraft CD, Levine RA, et al. Recommendations for evaluation of the severity of native valvular regurgitation with two-dimensional and Doppler echocardiography. J Am Soc Echocardiogr. 2003;16:777-802.

53. Rector TS, Cohn JN. Assessment of patient outcome with the Minnesota Living with Heart Failure questionnaire: reliability and validity during a randomized, double-blind, placebo-controlled trial of pimobendan. Pimobendan Multicenter Research Group. Am Heart J. 1992;124:1017-25.

54. Green CP, Porter CB, Bresnahan DR, Spertus JA. Development and evaluation of the Kansas City Cardiomyopathy Questionnaire: a new health status measure for heart failure. J Am Coll Cardiol. 2000;35:1245-55.

55. Spertus J, Peterson E, Conard MW, Heidenreich PA, Krumholz HM, Jones P, et al. Monitoring clinical changes in patients with heart failure: a comparison of methods. Am Heart J. 2005;150:707-15.

56. Supino PG, Borer JS, Franciosa JA, Preibisz JJ, Hochreiter C, Isom OW, et al. Acceptability and psychometric properties of the Minnesota Living With Heart Failure Questionnaire among patients undergoing heart valve surgery: validation and comparison with SF-36. J Card Fail. 2009;15:267-77.

57. Reynolds MR, Magnuson EA, Lei Y, Leon MB, Smith CR, Svensson LG, et al., Placement of Aortic Transcatheter Valves (PARTNER) Investigators. Health-related quality of life after transcatheter aortic valve replacement in inoperable patients with severe aortic stenosis. Circulation. 2011;124:1964-72.

58. McHorney CA, Ware JE, Raczek AE, Ware JE Jr. The MOS 36-Item Short-Form Health Survey (SF-36): II. Psychometric and clinical tests of validity in measuring physical and mental health constructs. Med Care. 1993;31:247-63.

59. Shaw, Ware JW, Johnson JA, Coons SJ. US valuation of the EQ-5D health states: development and testing of the D1 valuation model. Med Care. 2005; 43:203-20.

60. Ware J, Kosinski M, Keller SD, Ware J Jr. A 12-Item Short-Form Health Survey: construction of scales and preliminary tests of reliability and validity. Med Care. 1996;34:220-33.

61. Van Dijk D, Jansen EW, Hijman R, Nierich AP, Diephuis JC, Moons KG, et al. Cognitive outcome after off-pump and on-pump coronary artery bypass graft surgery: a randomized trial. JAMA. 2002;287:1405-12.

62. Akins CW, Miller DC, Turina MI, Kouchoukos NT, Blackstone EH, Grunkemeier GL, et al. Guidelines for reporting mortality and morbidity after cardiac valve interventions. Eur J Cardiothorac Surg. 2008;33:523-8.

63. Gotzmann M, Pljakic A, Bojara W, Lindstaedt M, Ewers A, Germing A, Mugge A. Transcatheter aortic valve implantation in patients with severe symptomatic aortic valve stenosis-predictors of mortality and poor treatment response. Am Heart J. 2011;162:238-45. e1.

64. Giugliano GR, Lotfi AS. Transcatheter aortic valve implantation: comparing apples to apples. J Invasive Cardiol. 2011;23:313-5.

65. Guetta V, Goldenberg G, Segev A, Dvir D, Kornowski R, Finckelstein A, et al. Predictors and course of high-degree atrioventricular block after transcatheter aortic valve implantation using the CoreValve Revalving System. Am J Cardiol. 2011;108:1600-5

66. Amat-Santos IJ, Rodes-Cabau J, Urena M, DeLarochelliere R, Doyle D, Bagur R, et al. Incidence, predictive factors, and prognostic value of new-onset atrial fibrillation following transcatheter aortic valve implantation. J Am Coll Cardiol. 2012; 59:178-88.

67. Fraccaro C, Buja G, Tarantini G, Gasparetto V, Leoni L, Razzolini R, et al. Incidence, predictors, and outcome of conduction disorders after transcatheter selfexpandable aortic valve implantation. Am J Cardiol. 2011;107:747-54.

68. Nuis RJ, Van Mieghem NM, Schultz CJ, Tzikas A, Van der Boon RM, Maugenest AM, et al. Timing and potential mechanisms of new conduction abnormalities during the implantation of the Medtronic CoreValve System in patients with aortic stenosis. Eur Heart J. 2011;32:2067-74.

69. Seiffert M, Conradi L, Baldus S, Knap M, Schirmer J, Franzen O, et al. Impact of patient-prosthesis mismatch after transcatheter aortic valve-in-valve 
implantation in degenerated bioprostheses. J Thorac Cardiovasc Surg. 2012; 143:617-24.

70. Stassano P, Di Tommaso L, Monaco M, Iorio F, Pepino P, Spampinato N, Vosa C. Aortic valve replacement: a prospective randomized evaluation of mechanical versus biological valves in patients ages 55 to 70 years. JAm Coll Cardiol. 2009;54:1862-8.

71. Rudski LG, Lai WW, Afilalo J, Hua L, Handschumacher MD, Chandrasekaran K, et al. Guidelines for the echocardiographic assessment of the right heart in adults: a report from the American Society of Echocardiography endorsed by the European Association of Echocardiography, a registered branch of the European Society of Cardiology, and the Canadian Society of Echocardiography. J Am Soc Echocardiogr. 2010;23:685-713, quiz 786-8.

72. Durack DT, Lukes AS, Bright DK. New criteria for diagnosis of infective endocarditis: utilization of specific echocardiographic findings. Duke Endocarditis Service. Am J Med. 1994;96:200-9. 